\title{
DA GUERRA ÀS DROGAS OU AOS USUÁRIOS? O DESMONTE DA POLÍTICA DE SAÚDE MENTAL, ÁLCOOL E OUTRAS DROGAS E SUA FUNÇÃO NO ENCARCERAMENTO*
}

\author{
Edilma Soares da Silva \\ Juliana Desiderio Lobo Prudencio \\ Luana da Silveira
}

\section{Introdução}

O Brasil é o país com a terceira maior população carcerária no mundo, acompanhado dos Estados Unidos da América e da China. De acordo com os dados do Sistema de Informações Penitenciárias do Departamento Penitenciário Nacional - INFOPEN ${ }^{1}$, o tráfico de drogas é o crime que mais encarcera no país. Nesse sentido, é fundamental conhecer de que forma o Governo Federal vem articulando suas políticas públicas sobre drogas, sobretudo, considerando os gastos diretos e indiretos.

De cunho proibicionista e criminal, marcadas pela seletividade, as políticas sobre drogas, nos campos da segurança pública e saúde, são justificadas como formas de proteção à sociedade e à saúde. Assim, torna-se crucial entender quais são os efeitos dessas políticas e quem são alvos preferenciais, problematizando questões de gênero, raça e classe, através da análise da "tríplice estrutura de dominação: o capitalismo patriarcal colonial” (LIMA, et al, 2019, p. 73). Essa perspectiva faculta o entendimento acerca da coexistência do homem branco rico, que menos é encarcerado/ internado no Brasil em um extremo e, no outro a mulher negra pobre, que tem estado nas funções subalternizadas de cuidado e de trabalho, inclusive nas instituições manicomiais e prisionais, e tem sido mais criminalizada, com o aumento crescente nas prisões, pelas políticas de drogas.

Dentre as forças que constroem as políticas, pretende-se abordar a relação entre os poderes da Psiquiatria e da Justiça no controle do uso de drogas, no processo de criminalização e medicalização de usuários/as, desde as primeiras décadas do século XX, até as últimas décadas, quando tem se acentuado. Em perspectiva foucaultiana, ressalta-se que essa aliança vem produzindo práticas que se legitimam através da apropriação da população usuária de drogas como os novos Anormais (perigosos e doentes) sobre quem se deve intervir.

Para as escolhas dos "destinos" das pessoas envolvidas com as drogas, quer vistas como usuárias e ou traficantes, os marcadores de raça, classe e gênero interferem nas decisões. Durante a segunda década dos anos 2000, com o fenômeno do crack, foi construído um novo regime de visibilidade que expressa a emergência por intervenções autoritárias, no atrelamento de usuáriotraficante, pelo estereótipo de que esse atrelamento é responsável pelo fortalecimento do tráfico de drogas ilícitas e de uma doença ilícita (AZEVEDO; SOUZA, 2017).

\footnotetext{
${ }^{*}$ DOI- 10.29388/978-65-81417-27-7-0-f.60-77

1 Para saber mais, disponível em: https://www.conectas.org/noticias/brasil-se-mantem-como-3o-pais-com-a-maior-populacaocarceraria-do-

mundo/\#: :text=Estados $\% 20$ Unidos $\% 20 \mathrm{e} \% 20$ China $\% 2 \mathrm{C} \% 20$ respectivamente,pela $\% 20$ Birkbeck $\% 20$ University $\% 20$ of $\% 20$ Lon don
} 
Nos últimos anos, especialmente para o enfrentamento do fenômeno do crack, esses processos de criminalização e medicalização sustentam as políticas e contribuem para a privação de liberdade em instituições de caráter prisional strictu senso dos considerados como traficantes; para cumprimento de medidas socioeducativas de jovens envolvidos na geopolítica do tráfico; e manicomiais, para usuários/as, cujas internações são movidas, predominantemente, por ações involuntárias e ou compulsórias no Brasil, situadas no movimento histórico da "Guerra às Drogas".

A aliança entre Psiquiatria e Justiça é marcada também pela perspectiva religiosamoralizante, tanto na lógica de entendimento, como na configuração de instituições que se consideram de tratamento, tendo como analisador a existência histórica das comunidades terapêuticas, pautadas na religiosidade, abstinência e laborterapia, que formalmente estão na rede de atenção psicossocial desde 2012, e são, em sua maioria, religiosas. Embora, oficialmente, as internações devam ser voluntárias, o aumento expressivo de internações compulsórias, por determinações judiciais, é analisador da função normalizadora para estabelecer diagnóstico, prognóstico, terapêutica e pena, e das práticas mais autoritárias que fazem o duplo processo de exclusão: doente/perigoso. (AZEVEDO; SOUZA, 2017).

O debate sobre a questão da droga é historicamente marcado pela Segurança Pública, assim como representa a luta por parte do Movimento da Luta Antimanicomial e Antiproibicionista para sua inclusão na Saúde Pública através do Sistema Único de Saúde (SUS). Com isso, a partir da revisão de literatura e levantamento documental, revela-se a importância da compreensão do/a usuário/a de drogas como sujeito de direitos e livre para os usos de substâncias no confronto com a noção de ilicitude de algumas drogas. Destacando assim, o papel penal no âmbito dos usos e tráfico de drogas, tão presente no debate da Segurança Pública. Tal fato apresenta-se como medida de contensão quer seja ela o cárcere e/ou a internação através das comunidades terapêuticas, em especial, como espaço para os sujeitos que, marcados pela raça, classe e gênero são encontrados portando drogas caracterizadas como ilícitas para o código penal brasileiro.

Já o SUS apresenta, através da atenção psicossocial, dispositivos de cuidado importantes para a Reforma Psiquiátrica e no cuidado de usuários/as de álcool e outras drogas como resposta as questões relacionadas aos usos de drogas (lícitas e ilícitas). No entanto, no atual contexto da necropolítica brasileira, a atenção ao usuário de drogas vem sendo marcada pelo encarceramento desses sujeitos.

Diante disso, o presente capítulo possibilita uma análise acerca do fenômeno droga na relação com os sujeitos usuários/as de drogas a partir do olhar antiproibicionista e antipunitivista que se reforça no reconhecimento da importância da análise com base na raça, classe e gênero como caminho para a compreensão da construção da atenção aos usuários/as de drogas no Brasil.

\section{Repressão, redução de danos e a atenção aos usuários/as de álcool e outras drogas}

O olhar sócio - histórico ancorado nos estigmas que os usos de drogas promovem sobre os usuários/as de drogas aqui compreendidas como ilícitas ${ }^{2}$, reforça o lugar dado a estes sujeitos

\footnotetext{
${ }^{2}$ Aquela substância que se localiza no código penal como proibida para consumo e venda.
} 
na construção de uma política de atenção inscrita no Sistema Único de Saúde (SUS). A droga enquanto substância passível de compra e venda, logo, uma mercadoria, é elemento histórico pertencente a nossa sociedade e ganha lugar da ilicitude com o avançar jurídico- penal sobre tal questão.

Desde as grandes navegações, a busca por drogas $^{3}$ se coloca como constituição da sociedade capitalista e reforça a construção mercantil sobre tais substâncias (CARNEIRO, 2005). É no século XIX, em especial no pós anos 1920 que se localiza a disseminação do proibicionismo e a instauração da "guerra às drogas", ou seja, o reconhecimento de que algumas substâncias possuem o poder de "viciar", matar e prender. No entanto, “(...) ao naturalizar a proibição como única forma de enfrentar o problema, cria-se uma falácia para sustentá-la: drogas são proibidas porque são ruins e são ruins porque são proibidas" (FIORE, 2012, p.14).

O proibicionismo às drogas trouxe para o debate a militarização no enfrentamento a produção e comércio de drogas, através da criação de uma polícia específica para este campo de ação, juntamente a um aparato jurídico normativo desenhado pela Segurança Pública que afirma ações de repressão aos usuários e traficantes de drogas. No mesmo contexto em que temos o crescimento de facções criminosas que, de forma organizada, compreende o poder mercadológico de certas substâncias e promove sua compra e venda, entendidas na nossa sociedade como tráfico de drogas.

Proibicionismo é uma forma simplificada de classificar o paradigma que rege a atuação dos Estados em relação a determinado conjunto de substâncias. Seus desdobramentos, entretanto, vão muito além das convenções e legislações nacionais. $\mathrm{O}$ proibicionismo modulou o entendimento contemporâneo de substâncias psicoativas quando estabeleceu os limites arbitrários para usos de drogas legais/positivas e ilegais/negativas. [...] O proibicionismo não esgota o fenômeno contemporâneo das drogas, mas o marca decisivamente (FIORE, 2012, p. 01).

Com isso, observa-se que dos anos de 1920 até anos 2000, no Brasil, a atenção para o tema droga esteve voltado para a repressão destas substâncias e contenção dos/as usuários/as e traficantes (seja no manicômio, manicômio judiciário, comunidades terapêuticas, unidades para cumprimento de medida socioeducativa ou prisões). Logo, é clara a invisibilidade dos usuários/as de drogas e suas demandas neste cenário, uma vez que tais sujeitos se tornam inimigos dado ao estereótipo marcado pela sua cor, raça e classe. Fazendo assim com que apenas se tenha a preocupação com a declaração da guerra às drogas.

Os usuários de drogas ganham certa notoriedade com a construção de uma atenção com base no cuidado e olhar sobre os usos de drogas a partir da estratégia de redução de danos (RD). A RD ganha espaço para o debate no Brasil a partir do final dos anos de 1980, pensando os riscos sociais e à saúde promovidos pelos usos de drogas de forma não orientada. De acordo com a redutora de danos, antropóloga, militante, pesquisadora e também usuária de drogas, membro da Rede Nacional Feminista e antiproibicionista - RENFA, Luana Malheiros (2018, p. 17)

${ }^{3}$ Carneiro (2005, p. 11) afirma "que significava produtos secos e servia para designar, dos séculos XVI ao XVIII, um conjunto de substâncias naturais utilizadas, sobretudo, na alimentação e na medicina". 
Agente Redução de danos: se assemelha a um agente comunitário de saúde, o agente redutor de danos atua em contextos de uso de drogas licitas e ilicitas, levando informações sobre o uso menos arriscado de drogas, bem como o compartilhamento de estratégias de autocuidado, promovendo também aproximação do usuário ou usuárias de drogas as redes de saúde e assistência. A categoria de -redutor de danos se fortalece no ano de 1997 a partir do surgimento da ABORDA, movimento social que trouxe a tarefa de dar maior visibilidade e legitimidade social aos usuário/as de drogas que estavam desenvolvendo o trabalho de agente comunitário.

A referida estratégia ganha espaço no campo das drogas como medida eficaz para a contenção do alto índice de contágio e disseminação do HIV e de hepatites, através da proposta das "trocas de seringas e agulhas" para os/as usuários/as de drogas injetáveis. Entretanto, tal estratégia também ganha espaço na defesa pela vida, protagonismo dos/as usuários/as de drogas, redução como não abstinência e inserção do tema droga na agenda da política de saúde.

A estratégia de redução de danos foi progressivamente incorporada à legislação brasileira sobre drogas, as políticas de saúde reconheceram a histórica lacuna assistencial prestada aos usuários de álcool e outras drogas. Nesse sentido, a partir da aprovação da Lei Federal no 10.216/2001, que legitimou o movimento de reforma psiquiátrica na área da saúde mental, os usuários de drogas foram efetivamente aceitos como de responsabilidade da saúde pública, mais especificamente, da saúde mental (MACHADO \& BOARINI, 2013, p. 588).

Cabe destacar que a inscrição do tema droga na política de saúde tem como marco a motivação de agentes políticos e trabalhadores da política de saúde mental inseridos no Ministério da Saúde e Secretarias de Saúde no Brasil, em especial a pessoa de Pedro Gabriel como Coordenador Nacional de Saúde Mental (de 2000 até 2010), como aponta Prudencio (2019). Tal falto impulsionou novos e/ou outros olhares sobre a questão dos/as usuários/as de drogas. Diante disso, tem-se a III Conferência Nacional de Saúde Mental, que é a primeira conferência a trazer o debate em tela e que aponta rumos necessários para a atenção neste campo, conforme apresentada em seu relatório.

Incorporar na rede de serviços do SUS ações de saúde mental dirigidas a populações específicas, tais como portadores de deficiências múltiplas, usuários abusivos de substâncias psicoativas (drogas) e dependentes químicos, na perspectiva da política de redução de danos, bem como reconhecer os aspectos culturais, étnicos e de gênero envolvidos no surgimento de um transtorno mental (BRASÍLIA, 2002, p. 9).

O tensionamento causado pela ala proibicionista convoca para a mesma data da III Conferência, de 11 até 15 de dezembro de 2001, o II Fórum Nacional Antidrogas com a proposta da criação de ações preventivas e de combate as drogas. $\mathrm{Na}$ tentativa exclusiva de esvaziamento da conferência que já se articulava sobre o tema da RD e garantir que a questão das drogas permanecesse no centro do debate da Segurança Pública. Neste mesmo cenário, temos, contraditoriamente, a aprovação da Política Nacional Antidrogas (PNAD) pelo Gabinete de Segurança Institucional que afirma a "guerra às drogas" declarando o empenho pela abstinência 
total, a repressão ao uso de drogas e a construção de uma sociedade sem drogas. Diante disso, é evidente a não incorporação da RD nesta política e apenas a legitimação do proibicionismo, o que mostra um contrassenso latente na comparação com a proposta apresentada pelo relatório da III Conferência.

Todavia, é em 2003, com a Política do Ministério da Saúde para a Atenção Integral a Usuários de Álcool e de outras Drogas (PAIUAD), instituída pelo Ministério da Saúde, que a RD passará a ser incorporada na atenção aos usuários de álcool e outras drogas como estratégica profícua na produção de cuidado em rede de saúde, no território, em defesa da vida e com o reconhecimento do/a usuário/a de drogas como sujeito de direitos.

A PAIUAD torna-se a referência para a produção de cuidado em conjunto com os/as usuários/as de drogas e sua família no território. A atenção apresentada pela política coloca os Centros de Atenção Psicossocial Álcool e outras Drogas como ordenadores da rede e convoca o/a usuário/a de drogas para o seu protagonismo no cuidado, através de ações interdisciplinares que possibilitem o olhar integral sobre o sujeito. Sendo assim, a PAIUAD busca romper com a abstinência como foco do cuidado, os estigmas causados pelos usos de substâncias e o olhar voltado para a droga, convidando assim a uma compreensão sobre o sujeito e sua relação com as substâncias (BRASIL, 2003).

Cabe tensionar que, até os anos 2000, a repressão era a forma como se pensava o trato do tema droga, exclusivamente. E, desde então, mostrou-se dois caminhos para o campo em debate: o do Ministério da Saúde e do Ministério da Justiça e Segurança Pública; uma vez que mesmo com o avanço no debate da RD através da instituição da PAIUAD, a ala proibicionista não mediu esforços para alavancar o debate e medidas que assegurem a abstinência total e a "guerra às drogas", e isto ganhará força em 2005, com a Política Nacional sobre Drogas.

A Política Nacional sobre Drogas instituída pela Secretaria Nacional de Política sobre Drogas (SENAD) surge em substituição a Política Nacional Antidrogas, a qual retrata o ápice do proibicionismo no Brasil com descrição de ações de cunho repressivo e punitivo no campo da droga com a demarcação de ações por "uma sociedade livre de drogas ilícitas e do uso incorreto de drogas lícitas". A Política Nacional sobre Drogas se aproxima da estratégia de redução de danos, porém não se afasta do tom repressivo dado até então, no entanto ela tenta realizar uma distinção entre usuários/as e traficantes de drogas, o que grosso modo, não atende, pois não conseguiu avançar na caracterização mais específica sobre o que representa portar drogas para consumo próprio ou comercialização. Esse é um dos graves erros desta política, deixando a cargo da autoridade policial e/ou o juiz a decisão sobre quem é usuário/a ou traficante de drogas, em uma sociedade que carrega o peso do estigma sobre o uso de tais substâncias e que reforça a raça como prerrogativa para o tráfico.

Diante disso, nota-se avanços relevantes no campo da Saúde Pública na atenção aos usuários de drogas, enquanto na Segurança Pública a referência que se instaura é da Política Nacional sobre Drogas. Sobre tais avanços temos a instituição da Portaria no 3088/2011 que apresenta a Rede de Atenção Psicossocial (RAPS), localizando a atenção a pessoa em sofrimento psíquico e/ou usuária de álcool e drogas na atenção em rede de saúde. Através dos sete pontos de atenção ${ }^{4}$ da RAPS, os quais valorizam a intersetorialidade e integralidade do cuidado em saúde e em redes de cuidado com o objetivo de ampliar e promover o acesso à atenção psicossocial

\footnotetext{
4 Os setes pontos de atenção encontrados na Portaria no 3088/2011 são: a atenção básica em saúde, a atenção psicossocial estratégica, a atenção de urgência e emergência, a atenção de caráter emergencial e transitório, a atenção hospitalar, a estratégia de desinstitucionalização e as estratégias de reabilitação psicossocial.
} 
através da garantia da articulação entre os serviços dos pontos de atenção descritos na portaria da RAPS.

Neste mesmo contexto temos uma ampliação nos serviços que compõem a RAPS com o financiamento para a instauração de novos Centros da Atenção Psicossocial (CAPS), como demonstra Gomes (2017, p.57): “em 2002, o país contava com 424 CAPS, passando para 2.209 nos anos de 2014, o que representa um aumento de mais de 500\%". No entanto, o cenário de crescimento não escamoteia a real realidade do trato governamental destinado aos usuários de álcool, crack e outras drogas. É no avançar da RAPS que se nota a deflagração de ações de cunho higienista nas cidades do Espírito Santo, São Paulo e Rio de Janeiro com o recurso a internação compulsória e o enaltecimento das Comunidades Terapêuticas (CTs), em especial nos anos de 2011 e 2012.

Tratar e isolar, assistir e se internar se confundiram. E pós- -tratamento se tornou um acompanhamento após a internação para evitar a recidiva na droga e para apoiar os ex-residentes em a convivência familiar e comunitária destes. Nesse sentido, as comunidades terapêuticas e a centralidade de um modelo de saúde hospitalocêntrico no país contribuíram para uma inversão no cuidado aos usuários de drogas, na medida em que a internação se tornou uma regra e não a exceção (LIMA, 2016, p. 162).

As CTs ganham espaço na Portaria no 3088/2011 e se expandem com a "Nova Política de Saúde Mental" que traz profundos retrocessos para a RAPS com a Portaria n ${ }^{\circ}$ 3588/2017 e Resolução $n^{\circ}$ 01/2018 do Conad, as quais assumem que o cuidado aos usuários de drogas deve ser realizado nas comunidades terapêuticas através da lógica hospitalocêntrica, médico centrada e medicalizada, ancorada pela abstinência em negação com a estratégia de redução de danos e cuidado no território. Com uma terapêutica centrada no culto religioso de cunho cristão e trabalho forçado (laborterapia).

Já no campo da Segurança Pública, em 2019 a Política Nacional sobre Drogas sofre alterações através do Decreto $n^{\circ} 9761 / 2019$ que institui a Lei 13.840/2019 a qual amplia o número de pessoas que podem solicitar a internação involuntária de usuários/as de drogas, sem alteração no serviço destinado para o cuidado neste campo. Logo, a referida lei também assume as comunidades terapêuticas como espaço de referência no cuidado em saúde mental no campo da droga e nega os CAPS AD (pois tal serviço se quer é citado na referida política) como espaço de atenção em saúde.

Com isso, observa-se que o proibicionismo às drogas e a "guerra às drogas" são campos de disputa na Saúde Pública e na Segurança pública desde a constituição de uma política de atenção aos usuários de drogas e na contenção do tráfico de drogas. No entanto, a formatação do cuidado e do controle da comercialização teve nuances e avanços distintos, conforme aqui apresentado: um calcado na estratégia de redução de danos e o outro na repressão. Contudo é a partir de 2017 que o caminho para se pensar o tema droga toma rumos iguais, seja na saúde ou na segurança pública, pois a lógica proibicionista ganha o contorno das ações nestas áreas e afirma que o caminho deve ser realizado via isolamento, distanciamento social e/ou não cuidado no território. Uma vez que a tônica da atenção passa a ser priorizada via comunidades terapêuticas e suas ações de cunho compulsório para os/as usuários/as de drogas e para os traficantes de drogas via encarceramento. 


\section{A política sobre drogas no Orçamento Público Federal: vigia, pune ou cuida?}

O Governo Federal apresenta, através do Ministério da Saúde e Segurança Pública, uma política de atenção ao campo das drogas que busca cumprir diversos objetivos, tais como: prevenção, combate ao uso, atendimento ao usuário, seja por meio de tratamento, como também em programas de acolhimento e assistência social. As políticas e programas implementados podem estar ligados a inúmeras funções como: assistência social, educação, justiça e saúde. Mas é importante saber, de acordo com o Orçamento Público Federal, quanto foi destinado a tais programas até o ano de 2021.

Em 2021, o Instituto de Política Econômica Aplicada (Ipea) publicou o relatório da análise das políticas públicas sobre drogas do Governo Federal. O relatório analisa o período de 2005 a 2019, a fim de apresentar quanto foi investido na prevenção, no cuidado e no combate às drogas, através da execução orçamentária dos Planos Plurianuais. O Plano Plurianual é o planejamento estratégico governamental juntamente com as diretrizes orçamentárias e os orçamentos anuais.

O Plano Plurianual compreende os 3 anos do governo atual e 1 ano do governo subseqüente. Dessa maneira, a análise dos dados foi feita com base nos seguintes governos: 2005 a 2010 o primeiro e segundo mandato do governo de Luis Ignácio Lula da Silva, 2011 a 2015 o primeiro mandato e o primeiro ano, até o golpe do governo de Dilma Roussef, 2016 a 2018 governo Michel Temer e 2019 governo Jair Messias Bolsonaro.

O principal objetivo desta pesquisa é mensurar quanto é gasto na política nacional voltada para as drogas pelo Governo Federal por meio da execução orçamentária. A principal dificuldade encontrada neste trabalho foi a impossibilidade de quantificar todas as ações desenvolvidas, uma vez que muitas delas são implementadas em conjunto com outras medidas que não são voltadas ao tema, ou porque se encontram em níveis de detalhamento na peça orçamentária cuja execução não se encontra disponível ou não se pode mensurar. Cabe aqui, portanto, uma crítica em relação ao planejamento orçamentário voltado a esta causa, pois parte dele se torna difícil de mensurar e, por consequência, de se analisar sua efetividade. Uma melhor distinção de diversas atividades voltadas para as políticas sobre drogas iria contribuir para uma melhor implementação e fiscalização dessas políticas públicas (IPEA, 2021, p.82).

Os gastos com a política sobre drogas foram desempenhando através de diversos ministérios, entre eles: o Ministério da Justiça e Segurança Pública; Ministério da Saúde; Ministério do Desenvolvimento Social; Ministério da Cidadania; Ministério das Relações Exteriores; Ministério da Mulher, da família, dos Direitos Humanos e Ministério da Educação; assim como suas secretarias de atenção a temática, que ao longo de 15 anos podem ter sofrido "alterações e junções", a partir de reformas ministeriais promovidas pelos governos a época. Para este estudo do Ipea (2021) foi identificado, então, os seguintes órgãos: Ministério da Saúde, Ministério da Justiça e Segurança Pública, Presidência da República, Ministério da Cidadania, Ministério do Desenvolvimento Social, Ministério das Relações Exteriores, Ministério da Mulher, 
da Família, dos Direitos Humanos, Secretaria dos Direitos Humanos, Defensoria Pública da União, Ministério da Educação, órgãos da Segurança Pública da União, Sistema Nacional de Atendimento Socioeducativo e Departamento Penitenciário Nacional ${ }^{5}$.

O quadro abaixo, adaptado da tabela original do Ipea $2021^{6}$, aponta para alguns gastos direto com a política de drogas, especificamente com os programas ligados ao Ministério da Saúde e Ministério da Justiça, optando-se por trazer dados de períodos de, pelo menos 1 ano, de cada um dos governos compreendidos nos períodos de 2005 a 2019. Ressalta-se ainda que o dotamento orçamentário é como base nos Planos Plurianuais:

Tabela 1: Gastos direto com a política de drogas pelo Ministério da Saúde

\begin{tabular}{|c|c|c|c|}
\hline Ano & Ministério da Saúde & Ministério da Justiça & Total Gasto \\
\hline $\mathbf{2 0 0 5}$ & 37.476 .199 & 143.801 .375 & 190.406 .004 \\
\hline $\mathbf{2 0 1 0}$ & 36.799 .602 & 202.145 .695 & 419.579 .691 \\
\hline $\mathbf{2 0 1 4}$ & 1.554 .365 .303 & 227.028 .614 & 1.781 .393 .917 \\
\hline $\mathbf{2 0 1 8}$ & 34.368 .533 & 412.860 .397 & 447.228 .930 \\
\hline $\mathbf{2 0 1 9}$ & 22.683 .341 & 421.230 .765 & 476.863 .640 \\
\hline
\end{tabular}

Fonte: IPEA, 2021

Destaca-se, para fins de conferência da soma total de cada ano, que existe ainda programas desempenhados diretamente pela própria Presidência da República que são R $\$$ 9.128.430 em 2005 e $\mathrm{R} \$ 11.208 .168$ em 2010, e ainda $\mathrm{R} \$ 169.426 .226$ em 2010 gastos pelo Ministério da Cidadania.

O relatório do Ipea (2021) apresenta não somente os gastos diretos com a política sobre drogas, mas também os gastos indiretos. Nesse montante são observados além dos gastos do Ministério da Justiça, Ministério da Saúde, também os do Ministério do Desenvolvimento Social que, posteriormente, será designado ao Ministério da Cidadania.

No Ministério da Saúde, os programas e ações sobre drogas são desenvolvidas pela Secretaria de Atenção à Saúde.

A principal contribuição do Ministério da Saúde consiste no fortalecimento da rede no aspecto da saúde mental, com ênfase no enfrentamento da dependência de crack e outras drogas. Além de garantir o auxílio-reabilitação psicossocial para pessoas em sofrimento mental, egressas de internação em hospitais psiquiátricos, inclusive em hospitais de custódia e tratamento psiquiátrico, cuja duração tenha sido por um período igual ou superior a dois anos. (IPEA, 2021, p.15)

Vejamos na tabela a seguir os gastos diretos e indiretos com drogas do Ministério da Saúde. Teremos com base os anos de 2005, 2010, 2014 e 2019. O quadro apresenta valor dotado e valor pago, o que foi previsto do programa e o que foi finalmente executado, como determina a Lei Orçamentária:

\footnotetext{
5Para maiores informações, disponível em: https://www.ipea.gov.br/portal/images/stories/PDFs/pubpreliminar/210510_analise_das_politicas_publicas_sobre_drogras_n o_orcamento_federa_2005_a_2019.pdf

${ }^{6}$ Para saber mais: https://www1.siop.planejamento.gov.br
} 
Tabela 2: Gastos diretos e indiretos com a política de drogas do Ministério da Saúde

\begin{tabular}{|c|c|c|}
\hline Ano & Valor Previsto & Valor Pago \\
\hline $\mathbf{2 0 0 5}$ & 86.295 .071 .341 & 78.424 .501 .929 \\
\hline $\mathbf{2 0 1 0}$ & 113.334 .679 .389 & 104.053 .220 .048 \\
\hline $\mathbf{2 0 1 4}$ & 141.969 .114 .212 & 126.018 .389 .557 \\
\hline $\mathbf{2 0 1 8}$ & 137.577 .328 .277 & 123.131 .205 .731 \\
\hline $\mathbf{2 0 1 9}$ & 136.003 .089 .498 & 126.850 .600 .568 \\
\hline
\end{tabular}

Fonte: IPEA, 2021

As ações do Ministério da Saúde são intersetoriais e nesses 15 anos, podemos destacar 8 ações especificamente sobre drogas:

Ação 8529 - Serviços Extra-Hospitalares de Atenção aos Portadores de Transtornos Mentais e de Transtornos decorrentes do Uso de Álcool e outras Drogas;

Ação 0843 - Auxílio-Reabilitação Psicossocial aos Egressos de Longas Internações Psiquiátricas no Sistema Único de Saúde;

Ação 20AI - Auxílio-Reabilitação Psicossocial aos Egressos de Longas Internações Psiquiátricas no Sistema Único de Saúde (De Volta Pra Casa);

Ação 6233 - Implantação e Implementação de Políticas de Atenção à Saúde Mental; Ação 20B0 - Atenção Especializada em Saúde Mental;

Ação 6177 - Implementação de Políticas de Atenção à Saúde do Adolescente e Jovem A Área Técnica de Saúde de Adolescentes e Jovens;

Ação 8535 - Crack é possível vencer;

Ação 8585 - Atenção à Saúde da População para Procedimentos em Média e Alta Complexidade (IPEA, 2021, p.16).

Como já dito no parágrafo anterior, as ações do Ministério da Saúde são intersetoriais, o que dificulta, de certa maneira, um levantamento mais preciso das ações destinadas a programas de saúde mental, diretamente, entre os anos de 2005 e 2007. No entanto, para o referido período foi previsto um total de $\mathrm{R} \$ 66.344 .710$ e foi, efetivamente, gasto $\mathrm{R} \$ 39.671 .499$ com Ações Extra-Hospitalares de Atenção a Pessoas em Sofrimento Psíquico Grave e Transtornos do Uso de Álcool e outras Drogas, conforme aponta análise do Ipea (2021). Outro ponto que merece destaque na análise deste capítulo é que, com a implantação e implementação de Políticas de Atenção à Saúde Mental, em 15 anos foi previsto um orçamento total de R\$111.472.342 e pago efetivamente $\mathrm{R} \$ 18.650 .566$.

Essa ação possui uma baixa execução orçamentária ao longo dos últimos 15 anos. Foram liquidados R \$20,4 milhões, o que representa apenas $18 \%$ da dotação orçamentária reservada à ação. O destaque vai para 2013, período em que se aplicou apenas $2 \%$ do total da dotação anual. Do valor aplicado nesta ação, $99,63 \%$ foram destinados para pagamento de custeio e 0,37\% direcionados para investimentos (IPEA, 2021, p.22)

Em se tratando do Ministério da Justiça e Segurança Pública, onde está alocada a Secretaria Nacional de Políticas Sobre Drogas - SENAD, instituída com base na Lei 11.343/2006, tem por missão garantir a aplicação da contenção da venda e compra de drogas, e 
"em razão de crimes relacionado às drogas e tem por objetivo promover a ordem jurídica com a gestão de ativos e reduzir a oferta de drogas no País", conforme apresenta o site do Ministério da Justiça e Segurança Pública", ainda a SENAD atua "em dois eixos no âmbito da política sobre drogas: redução da oferta de drogas e combate ao tráfico de drogas e crimes conexos; e gestão dos recursos apreendidos em decorrência de atividades criminosas relacionadas às drogas e crimes conexos".

Em se tratando de despesas relativas sobre drogas, destacam-se 8 programas: Programa 0662 - Combate à Criminalidade (PPA 2004-2007 e PPA 2008-2011), Programa 0665 - Gestão da Política Nacional Sobre Drogas (PPA 2008-2011), Programa 1453 - Nacional de Segurança Pública com Cidadania - PRONASCI (PPA 2008-2011), Programa 2060 - Coordenação de Políticas de Prevenção, Atenção e Reinserção Social de Usuários de Crack, Álcool e outras Drogas (PPA 2012-2015), Programa 2065 - Proteção e Promoção dos Direitos dos Povos Indígenas (PPA 2012- 2015), Programa 2070 - Segurança Pública com Cidadania (PPA 20122015), Programa 2081 - Justiça, Cidadania e Segurança Pública (PPA 2016-2020), Programa 2085 - Redução do impacto social do álcool e outras drogas: Prevenção, Cuidado e Reinserção Social (PPA 2016-2020). Para fins de comparação, trouxemos o orçamento previsto e liquidado pelo Ministério da Justiça e Segurança Pública, durante os 15 anos pesquisados: total previsto R \$ 232.825.057.217, total gasto $\mathrm{R} \$ 1$ 193.730.344.404.

As ações destes programas vão desde o combate ao crime organizado, ao tráfico ilícito de drogas e armas como também à ação Nacional de Enfrentamento ao Álcool e Outras Drogas, incluindo a Prevenção de Uso e/ou Abuso de Drogas. Essa ação, especificamente, foi também executada pelo Fundo Nacional Antidrogas. Entre os anos de 2005 e 2019 as ações de Combate ao Crime Organizado, ao Tráfico Ilícito de Drogas e Armas e à Lavagem de Dinheiro, tiveram uma dotação orçamentária de $\mathrm{R}$ \$2.924.027.565 e um gasto total de $\mathrm{R} \$$ 1.935.502.617.

A política para drogas concentra suas atividades no Ministério da Saúde, Ministério da Justiça e Segurança Pública e Ministério da Cidadania, que ao longo desses 15 anos vem assumindo os gastos direto com a política de drogas. O estudo que se apresenta busca mostrar uma análise no incentivo a ações realizadas pelo Ministério da Saúde e Ministério da Justiça e Segurança Pública no campo da droga, e deixa claro que o Ministério da Saúde, ao longo destes 15 anos, obteve $\mathrm{R} \$ 7,3$ bilhões para as ações nesta área de forma intersetorial, representando assim $0,44 \%$ dos gastos. Enquanto as ações realizadas pelo Ministério da Justiça e Segurança Pública garantiram, nestes 15 anos, uma soma de 3,3 bilhões que correspondem a 1,68\% do montante aplicado neste Ministério destinado ao gasto com drogas.

Diante disso, apesar do valor destinado as ações do Ministério da Saúde ser um valor maior em relação ao montante destinado ao Ministério da Justiça e Segurança Pública, a efetivação dos gastos no campo da droga se refere a uma porcentagem inferior. Ou seja, pode-se destacar, a partir da análise do Ipea (2021), que o valor correspondente ao Ministério da Justiça representa um percentual três vezes maior de investimento na relação analítica com o Ministério da Saúde. E que tal investimento destinado a efetivação da "guerra às drogas" não representou ações efetivas no campo da droga e ainda menor no trato de usuários/as e traficantes de drogas, pois, a longo prazo, nota-se uma redução grotesca no número de ação neste ministério na comparação com a crescente das ações realizadas pelo Ministério da Saúde.

\footnotetext{
${ }^{7}$ Para maiores esclarecimento, disponível em: https://www.justica.gov.br/sua-protecao/politicas-sobre-drogas/conheca-a-senad. Acesso em: 10 jun. 2021.
} 


\section{Usuário/a ou traficante: raça, classe e gênero como analisadores da criminalização e medicalização}

Os dados analisados anteriormente suscitam a necessidade de reflexão, também, sobre os efeitos do proibicionismo, enquanto política e lógica, nas dimensões macro e micropolíticas, nos campos da justiça e da saúde. Permitem o desmascaramento do discurso oficial que "prega" a proteção à saúde e a segurança pública, e demonstram a seletividade penal, de aplicação da lei e de cuidado, explicitando que a proibição do uso destas substâncias consiste na criminalização e/ou patologização das pessoas que compõem estes grupos étnicos, como parte da criminalização da pobreza baseada no mito da periculosidade de pessoas pobres, pretas e periféricas.

Quer se trate de justiça ou de medicina é a mesma ordem que está em jogo. Uma impõe sua manutenção inscrevendo-a na objetividade das leis e combatendo suas transgressões através de sanções. A outra detecta em cada pessoa uma distância com relação às suas normas e tenta anulá-las com remédios. (CASTEL, apud SILVA, 2013, p. 1)

Para desvendar a retórica humanista e prática punitivista, tanto no sistema penal como no SUS e no sistema socioeducativo, é crucial entender quais lógicas sustentam a seletividade penal, da aplicação da lei e do cuidado na distinção entre usuário/a e traficante. Conforme Ribeiro Júnior (2016, p.603)

Observa-se um amplo grau de discricionariedade na legislação que prevê a política criminal sobre drogas, ao passo que o art. $28, \int 2^{\circ}$, da lei federal 11.343/06 assevera que a distinção entre o usuário e o traficante de drogas é pautada nas condições pessoais e sociais da pessoa flagrada com a substância proscrita. Desta sorte, a política criminal sobre drogas é utilizada como subterfúgio para viabilizar práticas racistas e classistas.

A lógica proibicionista tem sido presente no sistema penal, transformando o uso e a circulação de drogas, que deveriam estar associados à questão social e às políticas públicas de saúde, e, ao invés disso, são reduzidas à questão penal, cuja proibição é a principal responsável pelo super encarceramento e por violações aos direitos humanos que resultam em superlotação carcerária. O processo de criminalização, pautado na distinção entre usuários/as e traficantes, denuncia que a política criminal enfoca na prisão de usuários/as de drogas e de pequenos traficantes em situação de grande vulnerabilidade social.

Com a Lei de Drogas (11.343/06), tem havido um constante do quantitativo de pessoas presas por tráfico em que a atuação das polícias se dá, predominantemente, por flagrante e autos de resistência, desembocando na prisão de milhares de pessoas as quais, em sua maioria, são negros, pobres, sem oportunidade de acesso a bom grau de ensino, presos, em sua maioria, desarmados e sozinhos. "Sendo representativa a presença de pequenos traficantes não violentos, primários, presos em flagrante sozinhos e desarmados em nosso sistema penitenciário [...]" (BOITEUX, 2014, p.84). Este perfil evidencia como a lógica repressiva enfoca na prisão de usuários/as, como se traficantes fossem, e de pequenos traficantes que atuam no varejo, sem 
vínculo com organizações criminosas, sem armas e em situação de extrema vulnerabilidade social.

Assim, a política de repressão, longe de proteger a saúde pública, é um mecanismo de criminalização da pobreza nas necessidades de regulamentação da vida na sociedade capitalista. A partir da perspectiva foucaultiana, Ribeiro Júnior afirma que "A biopolítica se vale de diversos dispositivos para perpetuar a dominação de um grupo sobre o restante. A criminalização de determinadas drogas, portanto, deve ser analisada a partir desta perspectiva: enquanto dispositivo de dominação" (2016, p.549).

O processo da criminalização de usuários/as e traficantes de drogas, desde o início, e sobretudo com a lei de 2006, tem sido a concretização do racismo como fundamento e objetivo não revelado das práticas proibicionistas. A seletividade não se expressa apenas na criminalização das substâncias, mas também na aplicação da lei e aos sujeitos/grupos considerados delituosos. Baseia-se em estereótipos do "elemento suspeito" ou da "atitude suspeita", que, no cotidiano do exercício do poder de polícia, criminalizam um grupo social vulnerável muito bem representado/visível no sistema carcerário: jovens pobres, em sua maioria negros, que vivem nas periferias dos grandes centros urbanos (CARVALHO, 2013). Este critério de distinção dá margem à reprodução de preconceitos sociais e raciais, que faz com que muitos dos/as usuários/as pobres sejam enquadrados como traficantes enquanto aqueles com condições mais privilegiadas sejam facilmente enquadrados no tipo penal do artigo 28.

Caraterizado por lógicas e práticas subjetivas de diferenciação, e que não oferecem critérios mínimos de segurança, bem como, o grande poder delegado às autoridades na tipificação da infração, sem qualquer critério garantista mínimo de proteção contra o arbítrio estatal punitivo desdobra em exponencial número de usuários/as presos como se fossem traficantes.

A partir da comparação dos presos e dos critérios de quantidades limitesQL's, é possível concluir que se o Brasil adotasse o critério de QLs da Espanha $69 \%$ das pessoas presas por posse de maconha e 19\% dos presos por posse de cocaína da população carcerária pesquisada no Estado de São Paulo teriam sido consideradas usuárias (e não traficantes de drogas) e não teriam sido presas. Tal estudo só evidencia o quão irracional é o nosso sistema de drogas ao enunciar formalmente a descarcerização do usuário e manter práticas encarceradoras dos mesmos (RIBEIRO JUNIOR, 2016, p. 605).

A discricionariedade existente na atual legislação sobre drogas em vigência no Brasil, segundo Ribeiro Júnior (2016), é um dispositivo que viabiliza a prática de racismo e a gestão da vida e da morte da juventude negra e periférica - principal foco da atual política sobre drogas. Além disso, é fundamental ressaltar que o proibicionismo é também um dispositivo de necropolítica, cuja passagem da biopolítica, conforme Mbembe (2018) inverte o binômio fazer viver e deixar morrer apresentado por Foucault para fazer morrer e deixar viver, é uma forma de governamentalidade também complexa, mas com consequências mais trágicas e "gera uma distribuição racional da morte através da criação da figura do inimigo social e que garante a impunidade daqueles que gerem estas práticas em nome da defesa da sociedade" (RIBEIRO JUNIOR, 2016, p. 600). 
Transversalizando macro e micropolítica, percebe-se a criação de um solo subjetivo que é marcado pela separação entre cidadão de bem e inimigo social, que leva à uma política de cárcere e morte em larga escala, via proibicionismo, como principal agente do genocídio do jovem negro e periférico. Gestado pelo Estado, tem a cumplicidade da mídia que produz pânico moral e a equivocada lógica da epidemia de drogas, noticiando e desumanizando a figura do traficante e usuário/a pobre, preto e periférico em contraponto com o/a usuário/a e traficante branco de classe média, o que é reproduzido pela sociedade. Assim, o/a usuário/a é sujeito a violências e exposto como inimigo interno da sociedade, "facilmente" identificado como usuário/a criminoso/a.

Os diferentes abusos e as diversas violências e violações cometidos contra estas pessoas são relevados a partir da construção de um estado de exceção sob o pretexto de combater o inimigo. Conforme afirma o autor, "A utilização das políticas criminais sobre drogas é um dispositivo que permite a criminalização de determinadas pessoas e justifica as inúmeras violências cometidas com o escopo de realizar o controle (de vida e de morte) destas pessoas" (ibidem, p. 600).

Desta forma, é preciso afirmar que o proibicionismo causa mais danos do que o uso de drogas mais problemático, revelando questões de raça, classe e gênero, uma vez que, no mundo todo, o sistema penal resulta de um processo de criminalização altamente seletivo e desigual de pessoas qualificadas como criminosas. E em relação às mulheres, a seletividade penal e de aplicação da lei afeta ainda mais a mulher negra, considerando a sua vulnerabilidade de gênero, social e econômica e como analisador do processo de discriminação racial, em uma tríplice estrutura de dominação caracterizado pelo "capitalismo patriarcal colonial, que sustenta a opressão, as desigualdades, a violência, a subalternização, a marginalização, a exploração, a vulnerabilidade e a exclusão social, e que coloca em um extremo o homem branco rico e no outro a mulher negra pobre" (LIMA, et al, 2016, p. 71).

Depois de 2006, o super encarceramento também tem sido caracterizado pela maior criminalização de mulheres, que em sua maioria não tinham antecedentes e foram detidas com pequenas quantidades de droga, por conta da nova norma. "Geralmente são mães solo, chefes de família para quem o aprisionamento dilacera esse núcleo familiar" (CONECTAS, 2014,s/p). Luciana Boiteux (2014) afirma que no período de 2007 a 2012 houve o aumento de 77,11\% de encarceramento de mulheres, tendo praticamente dobrado o número de presas por tráfico neste período. É necessário considerar que, embora em termos absolutos haja mais homens encarcerados por tráfico de drogas, em termos relativos, as mulheres estão super representadas entre os condenados por esta tipificação.

Deste modo, a criminalização das mulheres se dá pela aliança da estrutura patriarcal e pela guerra às drogas. Mulheres e meninas, na cadeia de abastecimento de drogas ilícitas, geralmente possuem ligações menores, entretanto, a aplicação do direito penal é pelo encarceramento por delitos relacionados à proibição das drogas, principalmente delitos não violentos, mais do que para qualquer outro crime.

De acordo com o Departamento Penitenciário Nacional - DEPEN (2018), e do INFOPEN Mulheres (2017), o país está na $4^{a}$ colocação de maior população carcerária feminina, sendo que em 2016 tinha 42.355 mulheres privadas de liberdade, em sua maioria jovens negras, entre 18 e 29 anos, com baixa escolaridade, solteiras e com filhos. Colocada como o outro do outro (outro do homem e o outro do branco), uma antítese da masculinidade e da branquitude, 
está na posição mais vulnerável na supremacia patriarcal e colonial do capitalismo e isso está escancarado no sistema prisional.

Desde o processo de tipificação ao encarceramento, as mulheres são atravessadas por uma maior vulnerabilização de gênero, raça e classe, para além da privação de liberdade, esgarçamento de laços afetivos, abandono familiar, entre outros. As mulheres reduzidas à "condição de homens que menstruam", são desumanizadas ao terem direitos fundamentais negados e suas demandas negligenciadas, uma face cruel da necropolítica com o braço do proibicionismo, que é ainda invisibilizada e pouco discutida socialmente.

O proibicionismo é hegemônico, também, no campo da atenção psicossocial voltada para usuários/as de drogas, especialmente desde 2012, com a entrada das comunidades terapêuticas na rede de atenção psicossocial- RAPS, com o tratamento baseado na privação de liberdade, abstinência, laborterapia e religiosidade. Temos assim, duplo processo excludente: da criminalização e de medicalização de usuários e usuárias de droga. Tal processo revela o projeto de super encarceramento e institucionalização em instituições totais (manicomiais, prisionais, socioeducativas) e da aliança perversa entre os poderes psiquiátrico, jurídico e religioso, cuja produção do inimigo social é marcada pelas lógicas da periculosidade, da incapacitação, da patologia, da moralização e demonização, e isenção/ violação de direitos.

A construção do inimigo sobre a figura do jovem pobre continua existindo, após o fim da ditadura, ocorrendo inclusive um recrudecimento do controle punitivo sobre drogas, com a substituição do antigo inimigo político, o subversivo, para o inimigo político criminal, o traficante. [...] reflexo deste controle desumano e desigual que é o controle penal proibicionista das drogas, que criminaliza o traficante e medicaliza o usuário [...]. (RIBEIRO JUNIOR, 2016, p. 600)

É importante ressaltar que a relação entre a Medicina Psiquiátrica e a Justiça no controle do uso de droga já vinha se constituindo desde as primeiras décadas do século XX. Nos últimos anos, percebe-se que o discurso construído acerca do uso de droga, especialmente do crack, rompe e desvia dos ideais da Reforma Psiquiátrica e promove o aumento vertiginoso/vergonhoso das estratégias segregacionistas, punitivas, num contínum entre puniçãotratamento-punição. Visto como epidemia grave e urgente ao/a usuário/a é tratado como perigoso, capaz de cometer delitos e atos violentos pra sustentar seu vício, sem autocontrole e incapaz de gerir sua própria vida. Respondendo à demanda higienista/ segracionista, em defesa da segurança e saúde pública e individual, a internação (voluntária, involuntária ou compulsória) é colocada como a principal estratégia. (SILVA, 2013)

A medicalização de usuários e usuárias de drogas tem se pautado na associação do uso de drogas com a periculosidade e com a loucura, também tida como perigosa - servem como justificativa para a internação em defesa da sociedade e suposta proteção, do mesmo modo que as instituições sócio-educativas e prisionais. O alvo dessas ações são, preferencialmente, as pessoas oriundas da classe trabalhadora, negra e pobre. Esse cenário é analisador do compromisso histórico da psiquiatria com código moral colonial, patriarcal e capitalista.

A rede de criminalização das drogas criou um circuito discursivo vicioso sobre o/a usuário/a de drogas, visto tanto como um "doente", como também um agente promotor do tráfico de drogas, portanto, um agente da rede criminosa. Nessa visão estereotipada "como 
aquele responsável pelo fortalecimento do tráfico de drogas ilícitas e, consequentemente, uma bizarra situação de uma doença ilícita" (AZEVEDO; SOUZA, 2017, p.494).

Para além da associação entre drogas e tráfico ilegal, foi preciso constituir um regime de verdade sobre o/a usuário/a de drogas que apontasse, a partir da figura do dependente químico e em grave situação de saúde, o destino de todos/as os/as usuários/as de drogas, prossegue o autor. Ao invés do estado de loucura ser confirmado pela existência dos delírios, passou-se a considerar o comportamento impulsivo, em que a justiça se torna cada vez mais terapêutica e a medicina, cada vez mais jurídica (AZEVEDO; SOUZA, 2017).

O tratamento tem sido pautado, hegemonicamente nas instituições totais, pela lógica da abstinência como tratamento, aliada ao ideal de um mundo livre das drogas. Assim, conforme os autores, quando a pessoa que usa drogas é reduzida à drogada/perigosa/delituosa/criminosa, seu lugar na saúde se dá compulsoriamente ou na condição de quem pretende parar de usar drogas, em que é convocada a falar e assumir o lugar de arrependida e comprometida a parar de usar drogas, a "ficar limpa".

\section{Considerações Finais}

A problematização da 'guerra às drogas' denota que essa política hegemônica tem produzido grandes impactos contraditórios, como o super-encarceramento, a grande internação, morte, entre outros. Do ponto de vista ético, legal e social, pode-se considerar que os efeitos sobre a saúde pública se tornam danosos duplamente, tanto pela exclusão e estigmatizaçãodo/a usuário/a de drogas, como pelas medidas impositivas, repressivas, compulsórias e punitivas que violam direitos humanos e produzem diversas violências.

Colocar em análise os territórios das denominadas "cracolândias" e do cárcere (penal ou da saúde), é explicitar como as medidas sanitárias podem ser tão repressivas quanto as medidas punitivas do sistema penal, pela falácia da epidemia e associação com a conduta violenta e criminosa.

[...] são vistas como terras sem lei habitadas por pessoas sem qualquer resquício de humanidade: não têm nome, rosto, nem história. São seres capazes de qualquer coisa em nome de seu vício, e que por isso ameaçam a sociedade. São aglomerados de corpos que colocam suas mazelas para serem vistas a olhos nus (SILVA, 2013, p. 19).

No contexto da última década, com o "fenômeno do crack", a legislação da Reforma Psiquiátrica tem sido utilizada para justificar a internação de usuários/as de drogas, contrariando a tentativa progressiva, em defesa da descriminalização e direitos de uso, do antiproibicionismo e articulação com as lutas antimanicomiais. Prevista em lei, a recorrência à internação compulsória tem sido equiparado o/a usuário/a de drogas a pessoa com sofrimento psíquico grave, baseado em laudo médico que ateste a situação clínica de "doente/ dependente/incapaz" de responder por si, mas cabe ao juiz, posteriormente, tomar a decisão e definir o destino.

Desvelar as forças do poder psiquiátrico e jurídico no campo das drogas permite o escancaramento dos processos de criminalização e medicalização, a partir da construção do inimigo e da retirada de seus direitos, dentre eles o da vida. São expressões da bio e necropolítica, que deixam viver e fazem morrer, também a partir da sua localização de classe, gênero e raça. 
Conforme Souza e Azevedo (2017), apesar do biopoder não ter inventado o racismo, a partir de teorias criminais e psiquiátricas ao longo do século $\mathrm{XX}$, permitiu o atrelamento a um conjunto de práticas voltadas para as raças ditas 'perigosas' e 'degeneradas'. Em nome da proteção à vida, tal poder possibilita uma investida estratégica sobre os/as usuários/as de crack em situação de rua, porque eles expressam, em seu quadro, uma relação direta com esse imaginário de atentado contra a vida, de periculosidade para os outros e para si, evocando as intervenções dos saberes e poderes agenciados.

Por último, aplicam-se as ações de internação e segregação de um grupo populacional acobertando, através de discursos tecnicistas, sua vocação totalitária -, apoiadas em ações profiláticas de defesa social contra a "degeneração", as quais representam tais indivíduos notadamente de caráter discriminatório e racista. Assim, pode-se afirmar que a guerra às drogas é aos sujeitos que a usam, portanto é mais nociva, do que o uso problemático.

\section{Referências}

AZEVEDO, A. O.; SOUZA, T. de P. Internação compulsória de pessoas em uso de drogas e a Contrarreforma Psiquiátrica Brasileira. Physis Revista de Saúde Coletiva, Rio de Janeiro, v. 27, n. 3, p. 491-510, 2017. Disponível em:

https://www.scielo.br/j/physis/a/T78xrxYK8j4bBYXDPSZWXvR/abstract/?lang=pt . Acesso em: 10 jun. 2021.

BOITEUX, L. Drogas e cárcere: repressão às drogas, aumento da população penitenciária brasileira e alternativas. In: SHECARIA, S. S. (Org.). Drogas: uma nova perspectiva. São Paulo: IBCCRIM, 2014.

BRASIL. Lei n ${ }^{\circ} 11.343$, de 23 de agosto de 2006. Institui o Sistema Nacional de Políticas Públicas sobre Drogas - Sisnad. Diário Oficial [da] República Federativa do Brasil, Brasília, DF, n. 143, p.2, seção 1, 24 de agosto de 2006. Disponível em:

http://www.planalto.gov.br/ccivil_03/_ato2004-2006/2006/lei/111343.htm. Acesso em: 04 maio 2021.

BRASIL. Lei no 13.840, de 5 de junho de 2019. Altera a Lei no 11.343, de 23 de agosto de 2006. Diário Oficial [da] República Federativa do Brasil, Brasília, DF, v. 108, p. 2, seção 1, 06 de junho de 2019. Disponível em: http://www.planalto.gov.br/ccivil_03/_ato2019-

2022/2019/lei/L13840.htm. Acesso em: 31 maio 2021.

BRASIL. Ministério da Justiça. Legislação e Políticas Públicas sobre Drogas. Brasília: Secretaria Nacional de Políticas sobre Drogas, 2005b. Disponível em: http://www.mds.gov.br/webarquivos/arquivo/cuidados_prevencao_drogas/obid/publicacoes/ Livros/Legisla \%C3\%A7\%C3\%A3o \%20e \%20Pol $\%$ C3\%ADticas $\% 20 \mathrm{P} \% \mathrm{C} 3 \%$ BAblicas $\% 20$ sobre \%20Drogas \%20no\%20Brasil.pdf. Acesso em: 28 maio 2021. 
BRASIL. Ministério da Saúde. Portaria GM/MS n 3.088, de 23 de dezembro de 2011. Diário Oficial [da] República Federativa do Brasil, Brasília, DF, v. 229, seção 1, p. 94, 27 de novembro de 2019. 2011a.

BRASIL. Ministério da Saúde. Portaria no 3.588, de 21 de dezembro de 2017. Diário Oficial [da] República Federativa do Brasil, Brasília, DF, seção 1, p. 236, 22 de dezembro de 2017.

BRASIL. Ministério da Saúde. Relatório da III Conferência Nacional de Saúde Mental. Brasília: Ministério da Saúde, 2002. Disponível em: http://bvsms.saude.gov.br/bvs/publicacoes /0210IIIcnsm.pdf. Acesso em: 27 maio 2021.

BRASIL. Ministério da Saúde. Secretaria Executiva. Coordenação Nacional de DST/Aids. A Política do Ministério da Saúde para a Atenção Integral a Usuários de Álcool e Outras Drogas. Brasília: Ministério da Saúde, 2003.

CARNEIRO, H. Transformações do significado da palavra "droga": das especiarias ao proibicionismo contemporâneo. In: VENÂNCIO, R. P.; CARNEIRO, H. Álcool e drogas na História do Brasil. São Paulo: Alameda; Belo Horizonte: Editora PUCMinas, 2005.

CARVALHO, S. A política criminal de drogas no Brasil: estudo criminológico e dogmático. 8 ed. São Paulo: Saraiva 2016.

CARVALHO, S. Nas Trincheiras de uma Política Criminal com Derramamento de Sangue: depoimento sobre os danos diretos e colaterais provocados pela guerra às drogas. Revista da EMERJ, Rio de Janeiro, v. 16, n. 63, p. 46-69, 2013. Disponível em: https://www.researchgate.net/publication/334899446_Nas_Trincheiras_de_uma_Politica_Crim inal_com_Derramamento_de_Sangue. Acesso em: 10 jun. 2021.

CONECTAS. Mapa das Prisões. Conectas: direitos humanos, [s.], 27 de novembro de 2014. Disponível em: http://www.conectas.org/pt/noticia/25378-mapa-das-prisoes. Acesso em: 11 abr. 2017.

CUNHA, A. S.; RIBEIRO, C. C.; PONTES, K. V.; et al. Publicação Preliminar - 2021 - Maio. Análise das Políticas Públicas sobre Drogas no Orçamento Federal - 2005 a 2019. IPEA, Brasília, 12 de maio de 2021. Disponível em:

https://www.ipea.gov.br/portal/index.php?option=com_content\&view=article\&id=37958\&Ite mid=457. Acesso em: 10 jun. 2021.

FIORE, M. O lugar do Estado na questão das drogas: o paradigma proibicionista e as alternativas. Novos estud. CEBRAP, São Paulo, v.92, 2012. Disponível em:

http:/ / www.scielo.br/scielo.php?script=sci_arttext\&pid=S010133002012000100002\&lng=en\&nrm=isso. Acesso em: 27 maio 2021.

GOMES, T. M. S. Reflexões sobre o Processo de Implementação da Política Nacional de Saúde Mental, Álcool e outras Drogas no Brasil Neoliberal. In: DUARTE, M. J. O.; PASSOS, R. G.; 
GOMES, T. M. S. Serviço Social, Saúde Mental e Drogas. Rio de Janeiro: Papel Social, 2017.

LIMA, C. F.; OLIVEIRA, T. F.; XAVIER, M. P.; et al. A tríplice estrutura de dominação: quem é o outro do outro no capitalismo patriarcal colonial? Mnemosine, Rio de Janeiro, v. 15, n. 2, p. 71-83, 2019. Disponível em: https://www.e-

publicacoes.uerj.br/index.php/mnemosine/article/view/48316. Acesso em: 10 jun. 2021.

MACHADO, L. V.; BOARINI, M. L. Políticas sobre drogas no Brasil: a estratégia de redução de danos. Psicol. cienc. prof., Brasília, v. 33, n. 3, p. 580-595, 2013. Disponível em:

http:/ / www.scielo.br/scielo.php?script=sci_arttext\&pid=S1414-

98932013000300006\&lng=en\&nrm=iso. Acesso em 23 maio 2021.

MALHEIROS, L. Tornar-se mulher usuária de crack: trajetória de vida, cultura de uso e políticas sobre drogas no centro de Salvador-BA. Dissertação (Mestrado em Antropologia) Universidade Federal da Bahia, Salvador, Bahia, 2018. Disponível em:

https://repositorio.ufba.br/ri/handle/ri/28468. Acesso em: 10 jun. 2021.

MBEMBE, A. Necropolítica. São Paulo, SP: n-1 edições, 2018.

RIBEIRO JUNIOR, A. C. As drogas, os inimigos e a necropolítica. Cadernos do CEAS, Salvador, n. 238, p. 595-610, 2016. Disponível em:

https://cadernosdoceas.ucsal.br/index.php/cadernosdoceas/article/view/251. Acesso em: 10 jun. 2021.

SILVA, C. C. R. A aliança entre justiça e psiquiatria no controle do uso de droga: medicalização e criminalização na berlinda. Revista EPOS; Rio de Janeiro - RJ, v. 4, n. 1, 2013. Disponível em: http://pepsic.bvsalud.org/scielo.php?script=sci_arttext\&pid=S2178-700X2013000100004. Acesso em: 10 jun. 2021. 